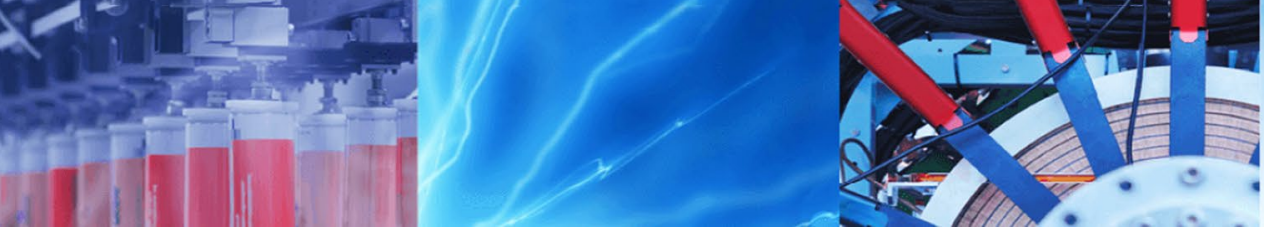

Research Article

\title{
Phenomenological kinetic model of the nano-bainitic steels to characterize the dynamics of the autocatalytic nucleation process
}

\author{
Minal Shah ${ }^{1,2}$ - Suchandan Kumar Das ${ }^{1} \cdot$ Ankita Pastor $^{3}$
}

Received: 28 December 2019 / Accepted: 2 March 2020 / Published online: 13 March 2020

(c) Springer Nature Switzerland AG 2020

\begin{abstract}
A kinetic model has been proposed in the present work, which formulates the dynamic nature of autocatalysis. The autocatalytic factor is quantified in the present work which involves interaction energy between bainite nucleus and stress field generated by existing bainite. This interaction energy provides the stored energy for autocatalytic nucleation and eventually reduces the nucleation barrier of bainite transformation. The change in Gibbs free energy due to carbon partitioning will also alter the autocatalytic nucleation with the bainite transformation. The model also evaluates the activation energy due to dislocation barrier, which is arising by solid solution strengthening of austenite. The slow kinetics at low transformation temperature is due to the larger activation energy of the dislocation barrier, which provides greater resistance to atomic displacement during transformation. The interaction energy between bainite nucleus and stress field generated by existing bainite was validated by determining the transformation shear strain exhibited in austenite which was found to be in the range as reported in the literature for displacive transformations.
\end{abstract}

Keywords Kinetics · Autocatalytic · Activation energy · Dislocation barrier · Interaction energy

\section{Introduction}

Bainite is probably the least understood product phase in steels. Due to the complexity in its transformation mechanism. Two schools of thoughts, exists till today, the diffusional and the displacive school, concerning the mechanism of bainite formation [1-3]. The diffusional growth model considers bainite to have reconstructive growth of both ferrite and carbides [4]. On the other hand, the displacive or diffusion less schools of thought consider bainite to grow without partitioning of alloying elements analogous to the martensitic transformation [5].

The present work is modeled considering the bainite to follow displacive mechanism similar to martensite. Bainite formation begins at prior austenite grain boundaries at the initial stages of transformation. Bainite formation continues successively by autocatalytic nucleation at the already transformed bainite. Ghosh and Raghavan [6] proposed the rate-controlling step in martensitic nucleation to be a thermally activated motion of dislocations. They determined the activation energies for nucleation under applied elastic stress or in work-hardened austenite [6]. Cohen also proposed the operational nucleation in martensitic transformations governs the reaction kinetics. It involves the growth start-up at preexisting embryos, followed by the fast chain of events triggered off after the growth process of martensite is initiated [7]. Ghosh and Olson [8] studied that the critical driving force for FCC to BCC martensitic nucleation can be termed by the sum of strain energy, defect-size dependent interfacial energy and composition dependent interfacial work.

Ghosh and Olson reported the kinetics of martensitic transformation has similarities with the kinetics of slip deformation in solid solutions. The universal nature of the

\footnotetext{
$\triangle$ Minal Shah, minalshah@nmlindia.org | ${ }^{1}$ Academy of Scientific and Innovative Research (AcSIR), Ghaziabad 201002, India. ${ }^{2}$ Materials Engineering Division, CSIR-National Metallurgical Laboratory, Jamshedpur 831007, India. ${ }^{3}$ Malaviya National Institute of Technology, Jaipur 302017, India.
} 
normalized activation energy versus normalized driving force relationship has been established for martensitic nucleation, which is consistent with nucleation rate control, by solute atoms acting as discrete obstacles to interfacial motion. The frictional work for FCC to BCC martensitic nucleation is modeled adopting a scaling between thermal and athermal contributions [9].

Meng et al. [10] studied the effect of internal stress on autocatalytic nucleation of martensite, which accompanies such morphological characteristics. They reported the stress field outside a transformed martensite plate could trigger other unstable martensite embryos to become stable nuclei and then grew up.

Various models were proposed by Matsuda and Bhadeshia [11] to solve the kinetics of bainite considering it to the displacive mechanism; however, they use empirical constants for the equations of activation energy. Singh [12] reported a model considering only nucleation at the austenite grain boundaries. It also assumes the number density to be dependent on constant B. However, Sidhu and Bhole [13] addresses this assumption and report it to be a temperature dependent. Van Bohemen and Sietsma [14] proposed a model consider autocatalytic factor to be a material constant. To address the issue of this model, they proposed another model considering the effectiveness of $\gamma / \gamma$ interface boundaries and the thickness of bainitic plates for determining the autocatalytic contribution to the overall transformation kinetics [15].

However, all the reported existing nucleation based models on bainite transformation uses several empirical parameters to account for the number density of autocatalytic nucleation sites and the number density of grainboundary nucleation sites [16]. The physical significance of these values obtained for the empirical constants is still ambiguous [17].

Ravi et al. [18] reported a unified model to predict the kinetics of isothermal bainite formation considering the degree of carbon enrichment of austenite. A physically based approach was considered to determine the autocatalytic nucleation. The autocatalytic factor is considered the difference in the activation energy for grain-boundary nucleation and autocatalytic nucleation is proposed here. The $\mathrm{K}_{\Gamma}$ parameter is used in the model to account for the variation in activation energy with composition. However, it does not gives a good validation with the values determined by Olson and Cohen [19]. A deeper understanding of the parameter is required. The model was modified and proposed by them considering the dynamic nature of autocatalysis. However, it has an empirical constant $(\theta)$ in the equation of autocatalysis, which does not give a physical significance [20].

The present model quantifies the autocatalytic factor considering the effect of the internal stress on autocatalytic nucleation of bainitic transformation. It quantifies the dynamic nature of autocatalytic factor. The model also uses the equation with more realistic correlation of activation energy and its dependence on the activation barrier, driving force, interfacial energy, and strain energy, etc.

\section{Model formulation}

\subsection{Nucleation rate}

Bainite laths may nucleate at pre-existing defects either at austenite grain boundaries $(\gamma / \gamma$ interface) or at the interphase of a previously nucleated bainite lath ( $a / \gamma$ interface). The latter may be interpreted as autocatalytic bainite nucleation [21]. Subsequently, autocatalytic nucleation occurs at the tip of the bainitic laths that have been formed because of the elastic and plastic strains generated in the subsequent surrounding austenite. By repetition of the process sheaf structure of bainite is formed. Total nucleation rate for bainite transformation from a fully austenitic phase, $\mathrm{dN} / \mathrm{dt}$, can be expressed as [18]:

$\frac{d N}{d t}=\left(\frac{d N}{d t}\right)_{G}+\left(\frac{d N}{d t}\right)_{A}$

where $\left(\frac{d N}{d t}\right)_{G}$ is the nucleation rate per unit volume due to the nucleation at austenite grain boundaries and $\left(\frac{d N}{d t}\right)_{A}$ is the nucleation rate per unit volume due to the autocatalytic nucleation.

In the present study, a transformation model for bainite transformation is developed on the basis of the displacive mechanism. In the displacive-based model, individual subunits are supposed to grow at much higher velocities [14]. In general, the model proposed here is the result of combination of well-established features nucleation of both phases bainite and martensite as reported in literature. Therefore, it leads to a specific temperature dependence of the number density of potential nucleation sites. According to displacive mechanism of bainite transformation, thermal activation is required for the two types of atomic processes [22-24]. Firstly, the dissociation of certain dislocation defects, which are already present in the austenite, phase to form bainite embryo. Secondly, carbon partitioning from the bainitic nucleus into the surrounding austenite matrix to create the necessarily available driving force for nucleation.

\subsubsection{Grain boundary nucleation rate}

The nucleation rate is usually expressed as an exponential function of the transformation temperature [25]. Using this approach, the nucleation rate due to grain boundary nucleation can be written as 
$\left(\frac{d N}{d t}\right)_{G}=\frac{k T}{h} N_{t G} \exp \left(\frac{-Q_{G}^{*}}{R T}\right)$.

The net molar driving force $\Delta G_{n}$ can beiven by Eq. $3[6,26]$ :

$\Delta G_{n}=\Delta G_{c h}+\Delta G_{e l}+2 V_{m o l} \frac{\sigma}{n d}+W_{\mu}$

where $\Delta G_{c h}$ is the molar chemical free energy for transformation from austenite and bainite, $\mathrm{G}_{\mathrm{el}}$ is the molar elastic strain energy $(400 \mathrm{~J} / \mathrm{mol}), \mathrm{V}_{\mathrm{mol}}$ is the molar volume of austenite $\left(6.8 \times 10^{-6} \mathrm{~m}^{3} / \mathrm{mol}\right), \sigma$ is the semicoherent interfacial energy $\left(200 \mathrm{~mJ} / \mathrm{m}^{2}\right), \mathrm{n}$ is the number of close-packed planes along the nucleus thickness $(n=16)$ and $d$ is the spacing between close-packed planes and $d$ [plane (1 1 1 ) in the FCC austenitic lattice, $\left.d=2.15 \times 10^{-10} \mathrm{~m}\right] . W_{\mu}$ is the athermal frictional energy and is taken to $W_{\mu}=0$ as reported by G. B. Olson and M. Cohen [19].

The present work considers the effect of carbon during autocatalytic nucleation and not on grain boundary nucleation. As the nucleation at grain boundary starts at initial stages of transformation when carbon partitioning has not started. Therefore, the change in Gibbs free energy due to carbon partitioning is not considered in grain boundary nucleation. The activation energy $\left(Q_{G}^{*}\right)$ of the austenite to bainite transformation can be calculated by using the following expression $[6,19,26]$ :

$Q_{G}^{*}=Q_{0}^{*}+K_{1} \Delta G_{n}$

where $Q_{G}^{*}$ is the activation energy for grain boundary nucleation and $Q_{0}^{*}$ is constant and is the activation energy in the absence of a driving force, $\mathrm{K}_{1}$ is a constant of proportionality obtained by a linear extrapolation of the values of $K_{1}$ from the values reported by Van Bohemen [14]. On evaluating the values of $\Delta G_{n}$ from Eq. 3 in Eq. 4 we get the activation energy for grain boundary nucleation as

$Q_{G}^{*}=Q_{0}^{*}+K_{1}\left(\Delta G_{c h}+\Delta G_{e l}+2 V_{m o l} \frac{\sigma}{n d}+W_{\mu}\right)$

\subsection{Dynamic nature of autocatalysis factor}

The autocatalytic factor during nucleation of bainite has a dynamic nature during the process of transformation. The dynamic nature is associated with its change in driving force available for bainite transformation with the progress of transformation as it partitions the carbon into the surrounding austenite. Therefore, the available free energy reduces eventually with the progress of transformation.

To quantify the autocatalytic factor, we need to understand the factors responsible for autocatalysis.
Formation of bainite lath will generate a stress field outside it in the surrounding retained austenite and it will be experience certain amount of strain due to the stress field. The bainite nucleating on the already formed bainite will have a stored energy, which will aid the bainite formation. This stored energy will be equivalent to the bainite nucleus/stress field interaction energy $\left(G_{\text {int }}\right)$ which is given by Cohen et al. [19], Messner et al. [27] and Meng et al. [10]. $G_{\text {int }}$ is given by Eq. 6 [10]: The schematic of creation of stress outside the bainite in surrounding austenite during autenite to bainite transformation is shown in Fig. 1a). The additional interaction energy of bainite nucleus/stress field increases the driving force for autocatalytic nucleation and is shown in Fig. 2.

$G_{i n t}=-\int \sigma_{i j}^{D} \varepsilon_{i j}^{T} d V$

where $\varepsilon_{i j}^{T}$ denotes the internal elastic strain state resulting from local strain incompatibility between bainite and austenite. Interaction energy is the corresponding internal stress state coupled to $\varepsilon_{i j}^{T}$ via Hooke's Law.

Messner et al. [27] further evaluated the $G_{i n t}$ to be given by Eq. 7:

$\mathrm{G}_{\mathrm{int}}=-\int \sigma_{\mathrm{ij}}^{\mathrm{D}} \varepsilon_{\mathrm{ij}}^{\mathrm{T}} \mathrm{dV} \approx-\frac{3 \mathrm{E}^{\gamma}}{2(1+v)}\left(\epsilon_{22}^{\mathrm{tr}}\right)^{2}$

where $E^{\gamma}=67,000 \mathrm{MPa}, v=0.4$

For example, $\epsilon_{22}^{t r}=0.043$ for polycrystalline equiatomic NiTi $[28,29]$.

Cohen, Kaufman, and Olson [10, 30-33] therefore suggested that the total Gibbs free energy change associated with the martensite could be written using Eq. 8. As bainite has a similar displacive mechanism to martensite, a similar equation can be used for the bainite transformation.

Therefore considering an extra energy involved for autocatalytic nucleation of bainite the net molar driving force for autocatalytic nucleation $\left(\Delta G_{n A}\right)$ is given by:

$\Delta G_{n A}=\Delta G_{c h A}+\Delta G_{e l}+2 V_{m o l} \frac{\sigma}{n d}+W_{\mu}+G_{i n t}$

The activation energy $\left(Q_{A}^{*}\right)$ of the austenite to bainite transformation can be calculated by using the following expression [6]:

$Q_{A}^{*}=Q_{0}^{*}+K_{1} \Delta G_{n A}$

where $Q_{A}^{*}$ is the activation energy for autocatalytic nucleation and $Q_{0}^{*}$ is constant and is the activation energy in the absence of a driving force, $\mathrm{K}_{1}$ is a constant of proportionality obtained by a linear extrapolation of the values of $\mathrm{K}_{1}$ from the values reported by Van Bohemen and Sietsman [14]. 

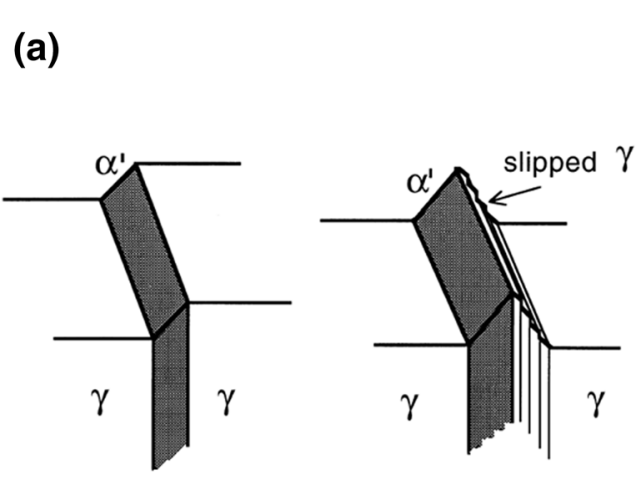

Stored Energy due to dislocation

$$
G_{\text {dis }}=-\int \sigma_{i j}^{D} \varepsilon_{i j}^{T} d V \approx-\frac{3 E^{\gamma}}{2(1+v)}\left(\epsilon_{22}^{t r}\right)^{2}
$$

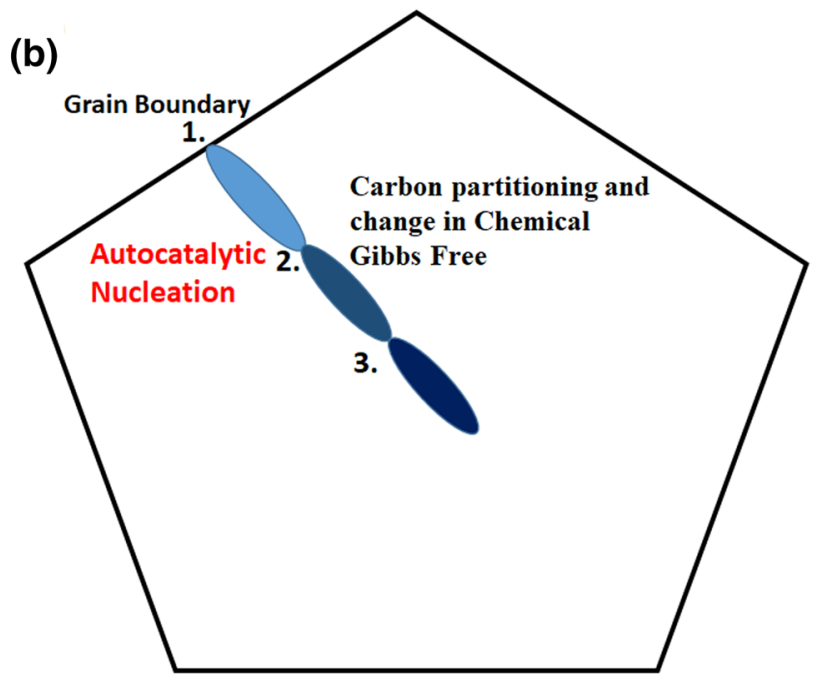

Carbon partitioning and change in Chemical Gibbs Free

$$
\Delta G_{c h}=-\Delta G_{c h A}\left(1-d *\left(\bar{w}+f \frac{(\bar{w}-s)}{(1-f)}\right)\right.
$$

Fig. 1 Schematic of a austenite to bainite transformation and generation of strain in the surrounding austenite $\mathbf{b}$ carbon partitioning at each bainite formation and increment of carbon in succeeding austenite

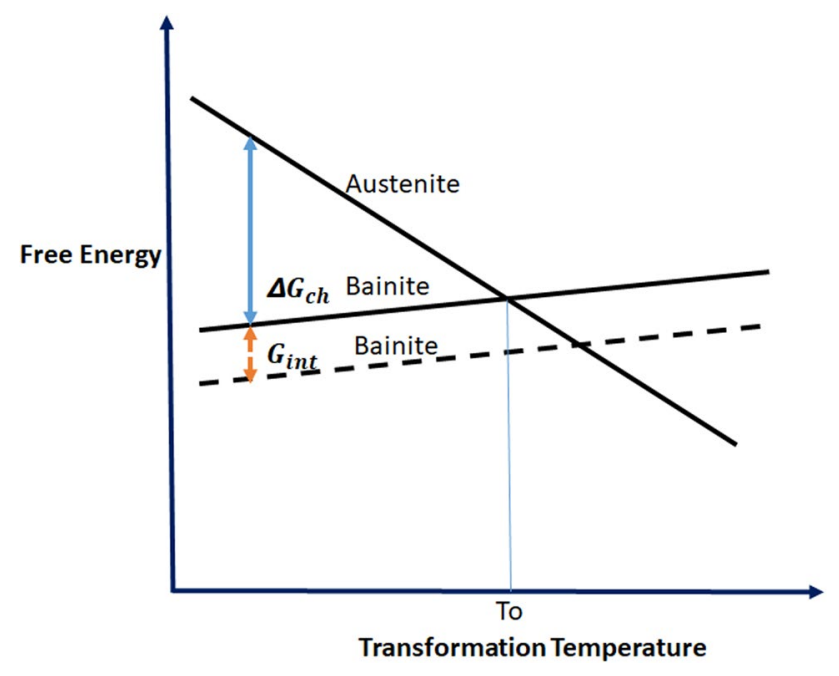

Fig. 2 The additional term $\mathrm{G}_{\text {int }}$ involved in autocatalytic nucleation increases its driving force for bainite transformation and aids transformation

In addition, it has to note the chemical driving force $\left(\Delta G_{c h}\right)$ will change with the progress of the bainite formation due to the partitioning of carbon from bainite to the surrounding austenite. Rees and Bhadeshia [34] proposed the change in Gibbs free energy as a function of fraction of bainite since the carbon enrichment of the untransformed retained austenite will reduce the Gibbs free energy change. The molar chemical free energy for transformation from austenite and bainite will vary with the carbon partitioned in surrounding retained austenite and is given by Eq. 10. The schematic of bainite transformation from grain boundary and successive by autocatalytic nucleation is shown in Fig. 1b. After each bainite formation, the carbon is partitioned to its surrounding austenite which will further transformed into bainite with the increased carbon.

$\Delta G_{c h A}=\Delta G_{c h A i}\left(1-d * w_{\gamma}\right)$

$\Delta G_{c h A i}$ is the initial molar chemical free energy for transformation from austenite to bainite at initiation of transformation. $d$ is the constant of proportionality which can be consider as fitting parameter in the model. The presence of defects in bainite and austenite will deviate the carbon concentration in austenite by some amount from the one expected by para-equilibrium line. $w_{\gamma}$ is the carbon concentration in untransformed austenite in weight fraction which is further evaluated and is shown in Eq. 11 .

$\Delta G_{c h A}=\Delta G_{c h A i}\left(1-d *\left(\bar{w}+f \frac{(\bar{w}-s)}{(1-f)}\right)\right)$

where $s$ is the fraction of carbon entrapped in bainite either in solid solution or in the form of the carbides (which depends on heat treatment conditions). $s$ can be replaced by $x_{b}$, which determines the carbon concentration in the bainite. $\bar{w}$ is the carbon concentration of the alloy in wt\%.

On evaluation of $G_{\text {int }}$ from Eq. 7 and value of $\Delta G_{c h A}$ from Eq. 10 in Eq. 8 we get, 


$$
\begin{aligned}
\Delta G_{n A}= & \Delta G_{c h A i}\left(1-d *\left(\bar{w}+f \frac{(\bar{w}-s)}{(1-f)}\right)\right) \\
& +\Delta G_{e l}+2 V_{m o l} \frac{\sigma}{n d}-\frac{3 E^{\gamma}}{4(1+v)}\left(\epsilon_{22}^{t r}\right)^{2}
\end{aligned}
$$

Nucleation rate for autocatalytic nucleation can be written as follows:

$\left(\frac{d N}{d t}\right)_{A}=\frac{k T}{h} N_{t A} \exp \left(\frac{-Q_{A}^{*}}{R T}\right)$

Evaluating values of $\Delta G_{n A}$ in Eq. 12 we get activation energy of autocatalytic nucleation $\left(Q_{A}^{*}\right)$ of the austenite to bainite transformation by using the following expression [6]:

$$
\begin{aligned}
Q_{A}^{*}= & Q_{0}^{*}+K_{1}\left[\Delta G_{c h A i}\left(1-d *\left(\bar{W}+f \frac{(\bar{W}-s)}{(1-f)}\right)\right)\right] \\
& +\Delta G_{e l}+2 V_{m o l} \frac{\sigma}{n d}-\frac{3 \boldsymbol{E}^{\gamma}}{\mathbf{4}(\mathbf{1}-\boldsymbol{v})}\left(\epsilon_{22}^{t r}\right)^{2}
\end{aligned}
$$

$Q_{A}^{*}$ will be different from $Q_{G}^{*}$ due to additional the nucleus/ stress field interaction energy involved and change in molar chemical free energy for transformation from austenite and bainite.

The difference of the activation energy for grain boundary nucleation and activation energy autocatalytic nucleation can be termed as $\mathrm{Q}^{*}$ and determined as follows:

$$
\begin{aligned}
\Delta Q^{*}= & Q_{G}^{*}-Q_{A}^{*} \\
\Delta Q^{*}= & K_{1 *} \Delta G_{c h}-K_{1}\left[\Delta G_{c h A i}\left(1-d *\left(\bar{W}+f \frac{(\bar{w}-s)}{(\mathbf{1}-f)}\right)\right)\right] \\
& +\frac{\mathbf{3} E^{\gamma}}{\mathbf{4 ( 1 - v )}}\left(\epsilon_{22}^{t r}\right)^{2} * K_{1}
\end{aligned}
$$

The physical basis of the autocatalytic factor is not evaluated in the reported literature till date. Ravi et al. [20] evaluates the autocatalytic factor in terms of physical quantity however, it does not quantifies the parameter responsible for an autocatalytic factor. Thus, the present model is more realistic. The present model quantifies the autocatalytic factor and considers the dynamic nature of autocatalysis due to change in carbon concentration with the successive formation of bainite.

\subsection{Potential nucleation sites}

Magee assumed in his derivation of the Koistinen-Marburger (KM) equation that with the reduction in temperature $d T$, the number of new martensite $(d N)$ sub-units formed per unit volume of austenite is proportional to , which is given by the increase in driving pressure due to reduction in the transformation temperature [35]. In line with this, we assume that for isothermal bainite formation the number density of pre-existing defects $N_{i}$ at a temperature $T$ depends linearly on the net driving pressure at $T$, which can be written as:

$N_{i}=\phi\left(G_{N}\left(T_{h}\right)-\Delta \boldsymbol{G}_{\boldsymbol{m}}(\boldsymbol{T})\right)=\zeta \boldsymbol{\Gamma}\left(T_{h}-\boldsymbol{T}\right)$

which shows that $\mathrm{Ni}=0$ at $\mathrm{T}=\mathrm{T}_{\mathrm{h}}$, and $\mathrm{N}_{\mathrm{i}}$ increases with undercooling.

In analogy with the work of Magee on martensite nucleation, $\phi$ can be expressed as [14,35]:

$\zeta=\frac{\alpha}{V_{b} \Gamma}$

where $V_{b}$ is the average volume of bainite sub-units, which is usually assumed to be constant $[36,37]$ as in the case of martensite formation [35]. Many experimental investigations have confirmed that the KM parameter is constant, and the good agreement between experimental data. The KM equation [14, 18] gives convincing support for the assumptions made by Magee, which have also been used in the present study. By combining Eqs. (17) and (18), it follows that the number density of pre-existing defects can be calculated according to [18]:

$N_{i}=\frac{m}{V_{b}}\left(T_{h}-\boldsymbol{T}\right)$

It is seen that $N_{i}$ is proportional to a parameter, which is, unfortunately, only experimentally investigated for martensite formation. In the case of martensite formation, $\mathrm{m}$ has a value in the range of $0.01-0.07 \mathrm{~K}^{-1}$ and depends slightly on the chemical composition $[37,38] . \mathrm{m}$ is the proportionality constant between number of bainite nucleation sites and the degree of undercooling.

The basic differences between nucleation of martensite and bainite as reported by Van Bohemen and Sietsma [14] is the density of pre-existing defects for martensite nucleation is independent of the prior austenite grain. However, in the bainite nucleation, the number density of $\gamma / \gamma$ interfaces play an important role.

Using Van Bohemen and Sietsma work, $m$ term in Eq. 19, can be replaced by term $b_{G}$ considering the effect of $\gamma / \gamma$ interfaces. The density of available $\gamma / \gamma$ interfaces depends on the volume fraction of remaining available austenite and the austenite grain size. The $b_{G}$ parameter can be written as follows [18]:

$b_{G}=\frac{Z \delta}{d} m f_{\gamma}$

where $Z$ is a geometrical factor, $\delta$ is the effective thickness of prior austenite grain boundary, $\mathrm{d}$ is the prior austenite 
grain size and $f_{\gamma}$ is the volume fraction of available remaining austenite.

The factor $\frac{z \delta}{d}$ accounts for the austenite grain boundary area per unit volume. For spherical austenite grains, $Z$ is supposed to be 6 . Van Bohemen and Sietsma [14] proposed that $d$ is the effective thickness of the austenite grain boundary which is defined as the atomic layers of a grain in the grain boundary region. It is assumed a few of outermost atomic layers in a grain, which participate in the nucleation process. Therefore, $\mathrm{d}$ can be consider equivalent to 2 atomic layers in each grain, which is equal to $1 \mathrm{~nm}$.

For autocatalytic nucleation, $b_{A}$ term is also dependent on the number density of $a / Y$ interfaces $\frac{z \delta}{d}$ and it can be expressed as a function of $m$ by Eq. 21 :

$b_{A}=\frac{Z \delta}{d} m f_{\gamma} f$

where $f$ in Eq. 21 is the volume fraction of bainite transformed.

The density of potential nucleation siteis also dependent on the size of the bainitic sub-units or laths. The size of the sub-units has an inverse relationship with the density of potential nucleation sites. The size of the sub-units also affects the remaining available retained austenite in which subsequent nucleation will take place.

\subsection{Carbon enrichment}

Carbon enrichment of surrounding austenite during the transformation of bainite influences largely to its kinetics as well as the fraction of bainite formation during transformation. The presence of silicon aids the partitioning of carbon in the surrounding retained austenite. The bainite transformation gets slower as it progresses due to carbon partitioning since the effective activation energy increases and therefore the effective undercooling reduces.

To encounter the effect of carbon enrichment, the following assumptions are being made:

1. Conservation of mass balance in bainite and austenite. The variation of carbon concentration of austenite may be given by Bhadeshia and Edmond work [39] as follows:

$w_{\gamma}=\bar{w}+f \frac{(\bar{w}-s)}{(1-f)}$

where $s$ is the fraction of carbon entrapped in bainite either in solid solution or in the form of the carbides (which depends on heat treatment conditions). s can be replaced by $w_{b}$ (in wt\%), which determines the carbon concentration in the bainite. $\bar{w}$ is the carbon concentration of the alloy in wt\%.

2. The bainite transformation temperature $\left(T_{h}\right)$ reduces linearly with the increase in carbon content in austenite during bainitic transformation. $T_{h}$ can be expressed by Eq. 23:

$T_{h}=T_{h \bar{x}}-C_{1} w_{\gamma}$

$T_{h}=T_{h \bar{x}}-C_{1} \frac{\left(\bar{w}-f w_{b}\right)}{(1-f)}$

$T_{h \bar{X}}$ is the $T_{h}$ Temperature at the beginning of the transformation i.e. $\mathrm{f}=0$ and $w \gamma=\bar{w}$ and $C_{1}$ is a proportionality constant relating $T_{h}$ and carbon concentration in austenite $\left(w_{\gamma}\right)$ in wt\% is determined using thermodynamic calculations (MUCG 83) software [40]. $w_{b}$ is the carbon concentration in bainite in wt $\%$.

\subsection{Austenite fraction}

The fraction of remaining available austenite, $\mathrm{f}_{\mathrm{\gamma}^{\prime}}$ is important to estimate the density of potential nucleation sites [18]. $f_{y}$ is a fraction of the total untransformed austenite in which bainite formation can proceed. Due to the carbon enrichment of austenite during of transformation, some fraction of austenite may not participate in the bainite reaction. This unavailable fraction of austenite would not contain any potential nucleation sites, which will lead to new nucleation events, and this fraction needs to be subtracted while calculating the overall nucleation rate. In this work, the unavailable austenite is defined as the fraction of austenite in which bainite formation cannot occur due to its stabilization due to carbon enrichment.

Using the principles of incomplete reaction phenomenon and as formulated by work A.M Ravi et al. [18]. We can write the equations as:

$f_{\gamma}=(1-f) \frac{\left(T_{0}^{\prime}-T\right)}{\left(T_{0 \bar{X}}^{\prime}-T\right)}$

$T_{0}^{\prime}=T_{0 \bar{x}}^{\prime}-C_{2} f \frac{\left(\bar{X}-X_{b}\right)}{(1-f)}$

$T_{0 \bar{X}}^{\prime}$ is the $T_{0}^{\prime}$ Temperature at the beginning of the transformation i.e. $\mathrm{f}=0$ and $x \gamma=\bar{x}$ and $C_{2}$ is a proportionality constant relating $T_{0}^{\prime}$ and carbon concentration in mole fraction using thermodynamic calculations in mole fraction by MUCG 83 software [40]. 


\subsection{Kinetic model}

With the help of the aforementioned governing equations, the framework of the proposed kinetic model is given here. The overall nucleation rate can be given as:

$$
\begin{aligned}
& \frac{d N}{d t}=(1-f) \frac{\left(T_{0}^{\prime}-T\right)}{\left(T_{0 \bar{x}}^{\prime}-T\right)}\left[1+\exp \left(\frac{\Delta Q *}{R T}\right) f\right] \kappa \\
& \kappa=\frac{k T}{h} \frac{Z \delta}{d} \frac{m}{V_{b}}\left(T_{h}-T\right) \exp \left(\frac{-Q_{G} *}{R T}\right) \\
& \frac{d f}{d t}=\frac{d N}{d t} V_{b}
\end{aligned}
$$

Ravi et al. [18] quantify the autocatalytic factor but it did not state the factors and physical significance of the term $\Delta \mathrm{Q} *$. The dynamic nature of the autocatalytic factor is also being addressed in his work [20]. It uses a proportionality constant to address it. However, such formulation has no physical significance. The dynamic nature of autocatalysis is attempted to address in the present work with its origin of physical significance.

The acceleration of bainite kinetics due to autocatalysis can be interpreted in terms of the difference in activation energy for grain-boundary nucleation and autocatalytic nucleation as described above. The difference in the activation energy of the two is associated with internal stress field developed by a plate on embryo and change in Gibbs free energy due to carbon partition and initial Gibbs free energy.

$\beta=\exp \left(\frac{K_{1 *} \Delta G_{c h}-K_{1} *\left[\Delta G_{c h A}\left(1-d *\left(\bar{W}+f \frac{(\bar{w}-s)}{(1-f)}\right)\right)\right]+\frac{3 E^{r}}{2(1+v)}\left(\epsilon_{22}^{t r}\right)^{2} * K_{1}}{R T}\right)$

$\Delta Q^{*}=Q_{G}^{*}-Q_{A}^{*}$

$$
\begin{aligned}
\Delta \mathrm{Q}^{*}= & K_{1} * \boldsymbol{\Delta} G_{c h}-K_{1} *\left[\Delta G_{c h A}\left(1-d *\left(\bar{W}+f \frac{(\bar{w}-s)}{(1-f)}\right)\right]\right. \\
& +\frac{\mathbf{3} \boldsymbol{E}^{\gamma}}{\mathbf{2}(\mathbf{1}+\boldsymbol{v})}\left(\boldsymbol{\epsilon}_{\mathbf{2 2}}^{\text {tr }}\right)^{2} * K_{1}
\end{aligned}
$$

$T_{h}$ and $T_{0}^{\prime}$ can be tracked using Eq. 24 and Eq. 26 respectively.

$\mathrm{W}_{\mathrm{b}}, Q_{G}^{*}, \mathrm{~K}_{1}$ and $Q_{d}$ are fitting parameters used in this model. $w_{b}$ will always have value in the range of 0 to $\bar{w}$. $\mathrm{w}_{\mathrm{b}}$ is the fitting parameter in the model and the model therefore considers the super saturation of carbon as it states $w_{b}$ will always have value in the range of 0 to $\bar{w}$. $\mathrm{w}_{\mathrm{b}}$ will be tune in the model to match the maximum volume fraction of bainite of the experimental value. The constants $T_{0 \bar{X}^{\prime}}^{\prime} C_{1}$ and $C_{2}$ are calculated using MUCG 83 software which uses MTData [40].

Equation 27 is very similar to the expression of the nucleation rate proposed by other authors [14-20]. However, the main differences in the proposed model are that it quantifies all the empirical constants and it interprets its physical significance, especially the autocatalytic parameter. Earlier models of bainite kinetics based on displacive mechanism accounts the autocatalytic nucleation using the constant factor $\beta$ as the autocatalytic parameter. Comparing this with Eq. 32, it can be seen that $\beta$ is determined as [18]:

$\beta=\exp \left(\frac{\Delta \mathrm{Q} *}{R T}\right)$
The activation energy of the carbon diffusion is given by expression 34 [41].

$Q c=144.3-15.0 W c+0.37 W c^{2}$

$\mathrm{W}_{\mathrm{c}}$ is the weight percentage of carbon in the steel.

$Q_{0}^{*}$ is a constant and is the activation energy for dislocation motion in the absence of a driving force which is the summation of activation energy of the carbon diffusion $(Q c)$ and activation energy due to the dislocation barrier $\left(\mathrm{Q}_{\mathrm{d}}\right)$ [18].

$Q_{0}^{*}=Q c+Q_{d}$

\subsection{Numerical solution}

The kinetics of bainite is simulated numerically by solving the aforementioned governing equations using a gear implicit scheme fourth-order Runge-Kutta Matlab solver to solve the stiff differential equation solver. This has been implemented in Matlab by invoking the ode15s solver in the time domain with initial conditions $f=0$ at $t=0$ and simulations are run to determine kinetics at various temperatures.

Gear method $[42,43]$ is used for solving non-linear dynamics differential equations. Gear method provides higher calculation precision and efficiency, and change step size automatically. Implicit solvers provide much 
greater stability for the oscillatory behavior and are more efficient than explicit solvers for solving linearly implicit systems. Although, implicit solvers are computationally more expensive as they generate a Jacobian matrix and solve a set of algebraic equations at every time step using a Newton-like method. To reduce such extra cost, the implicit solver offers a Solver Jacobian method that allows improving the simulation performance of the implicit solvers [44]. Stiff differential equations are numerically unstable unless the step size is extremely small. For stiff problems, defining the Jacobian matrix using odeset is important. A stiff solver uses the Jacobian matrix to determine the local behavior of the ODE during integration, and usage of the Jacobian matrix is critical for efficiency and reliability.

\section{Results and discussions}

\subsection{Grain boundary nucleation}

The formulated model was tested and the experimental data are compared with model values as shown in Fig. 3. One of the main aims of this work was to develop an improved model with all energy values involved in transformation and to predict isothermal transformation kinetics of alloys at different temperature with keeping the factor of the degree of carbon enrichment in retained austenite.

The activation energy for grain boundary nucleation $\left(Q_{G}\right)$, the nucleus/stress field interaction energy $\left(G_{\text {int }}\right)$, and $\mathrm{w}_{\mathrm{b}}$ (carbon concentration in bainite in mole fraction) are sensitive parameters used for the validation of modeled data with the experimental data. The activation energy for grain boundary nucleation was determined to be $1.55 \times 10^{5} \mathrm{~J} / \mathrm{mol}$ for Alloy 1 at $200{ }^{\circ} \mathrm{C}, 1.57 \times 10^{5} \mathrm{~J} / \mathrm{mol}$ for Alloy 1 at $250{ }^{\circ} \mathrm{C}$ and $1.58 \times 10^{5} \mathrm{~J} / \mathrm{mol}$ at $300^{\circ} \mathrm{C}$. The activation energy for carbon diffusion in Alloy 1 is evaluated using Eq. 34 and is found be $130 \mathrm{~kJ} / \mathrm{mol}$ [41]. The activation energy by dislocation barrier $\left(\mathrm{Q}_{\mathrm{d}}\right)$ determined using Eq. 4 and 38 at $200{ }^{\circ} \mathrm{C}, 250^{\circ} \mathrm{C}$ and $300^{\circ} \mathrm{C}$ for Alloy 1 are $64.38 \mathrm{~kJ} / \mathrm{mol}, 63 \mathrm{~kJ} / \mathrm{mol}$ and $58.313 \mathrm{~kJ} / \mathrm{mol}$ respectively (Table 1). It can be observed that with the rise in transformation temperature the activation energy due to dislocation barrier reduces. This concludes that kinetics of bainite transformation is more dependent on activation energy by dislocation barrier rather than the quantity of driving force available for bainite transformation. As the driving force available was maximum at $200^{\circ} \mathrm{C}(-2325 \mathrm{~J} /$ $\mathrm{mol}$ ) as compared to $-1954 \mathrm{~J} / \mathrm{mol}$ at $250^{\circ} \mathrm{C}$ and $-1580 \mathrm{~J} /$ mol at $300^{\circ} \mathrm{C}$. However, at $200^{\circ} \mathrm{C}$ the alloy 1 has the slowest kinetics among all the temperature due to its greater activation energy due to dislocation barrier.
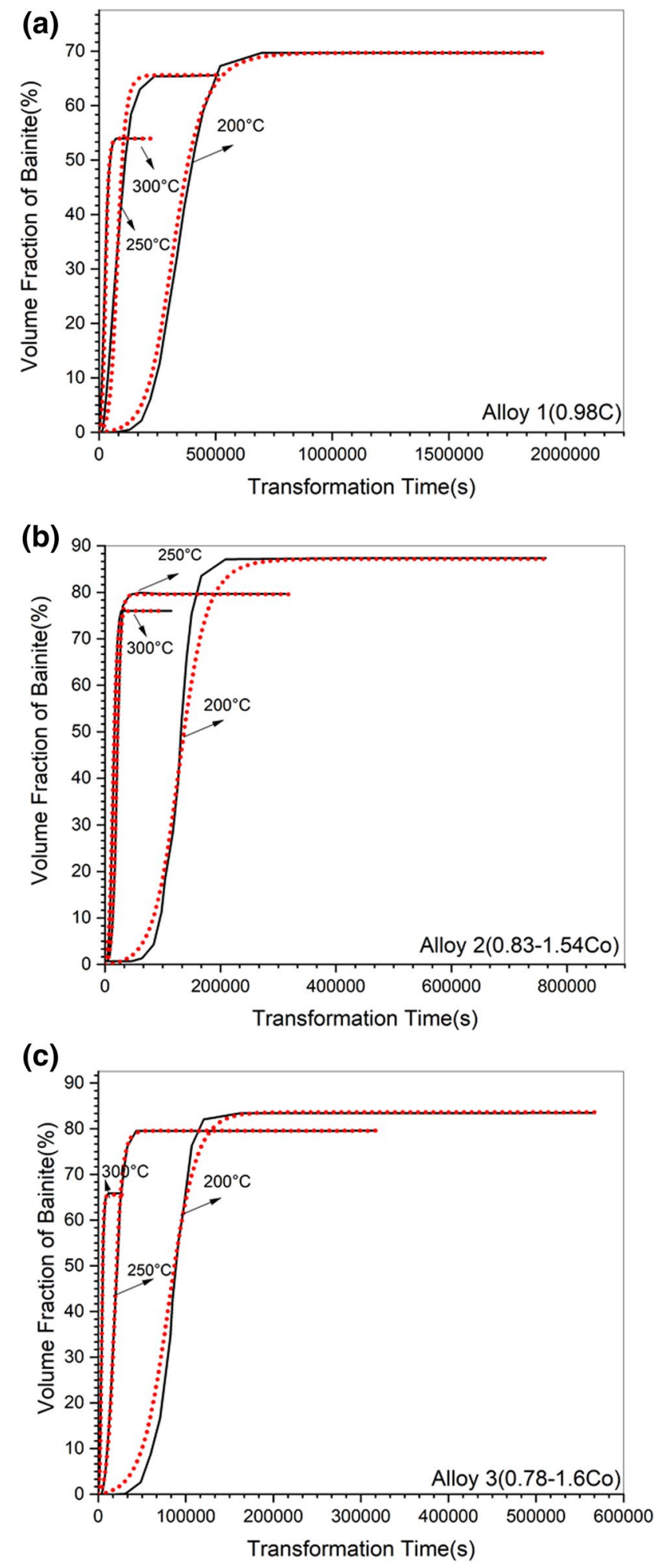

Fig. 3 Experimental [45] (solid lines) and calculated kinetics (markers) of Alloy 1, Alloy 2 and Alloy 3

Similarly, for Alloy 2 the activation energy for grain boundary nucleation was determined to be $1.50 \times 10^{5} \mathrm{~J} /$ mol for Alloy 2 at $200{ }^{\circ} \mathrm{C}, 1.51 \times 10^{5} \mathrm{~J} / \mathrm{mol}$ for Alloy 1 at 
Table 1 The composition in weight percentage (wt\%) of alloys [45] investigated in present work

\begin{tabular}{lllllllll}
\hline Alloy & $\mathrm{C}$ & $\mathrm{Cr}$ & $\mathrm{Si}$ & $\mathrm{Mn}$ & $\mathrm{Mo}$ & $\mathrm{Co}$ & $\mathrm{Al}$ & $\mathrm{V}$ \\
\hline Alloy 1 (0.98C) & 0.98 & 1.26 & 1.46 & 1.89 & 0.26 & 0 & 0 & 0.09 \\
Alloy 2 (0.83-1.54Co) & 0.83 & 1.02 & 1.57 & 1.98 & 0.24 & 1.54 & 0 & 0 \\
Alloy 3 (0.78-1.6Co) & 0.78 & 0.93 & 1.49 & 1.95 & 0.24 & 1.6 & 0.99 & 0 \\
\hline
\end{tabular}

$250^{\circ} \mathrm{C}$ and $1.56 \times 10^{5} \mathrm{~J} / \mathrm{mol}$ at $300^{\circ} \mathrm{C}$. The activation energy for carbon diffusion in Alloy 2 is evaluated using Eq. 34 and is found be same $134 \mathrm{~kJ} / \mathrm{mol}$ [41]. The activation energy by dislocation barrier determined using equation at $200{ }^{\circ} \mathrm{C}$, $250{ }^{\circ} \mathrm{C}$ and $300{ }^{\circ} \mathrm{C}$ for Alloy 2 are $54.59 \mathrm{~kJ} / \mathrm{mol}, 52.691 \mathrm{~kJ} /$ $\mathrm{mol}$ and $52.518 \mathrm{~kJ} / \mathrm{mol}$ respectively. The activation energy for grain boundary nucleation for Alloy 3 was determined to be $1.46 \times 10^{5} \mathrm{~J} / \mathrm{mol}$ for Alloy 2 at $200{ }^{\circ} \mathrm{C}, 1.48 \times 10^{5} \mathrm{~J} /$ mol for Alloy 1 at $250^{\circ} \mathrm{C}$ and $1.52 \times 10^{5} \mathrm{~J} / \mathrm{mol}$ at $300^{\circ} \mathrm{C}$. The activation energy for carbon diffusion in Alloy 3 is evaluated using Eq. 34 and is found be same $136 \mathrm{~kJ} / \mathrm{mol}$ [41]. The activation energy by dislocation barrier determined using equation at $200^{\circ} \mathrm{C}, 250^{\circ} \mathrm{C}$ and $300^{\circ} \mathrm{C}$ for Alloy 3 are $53.844 \mathrm{~kJ} / \mathrm{mol}, 53.607 \mathrm{~kJ} / \mathrm{mol}$ and $50.7 \mathrm{~kJ} / \mathrm{mol}$ respectively.

It can be observed that the reduction in transformation temperature the activation energy due to dislocation barrier increases and so it has decelerated kinetics at low temperature. This concludes that kinetics of bainite transformation is also significantly dependent on activation energy by dislocation barrier rather than the quantity of driving force available for bainite transformation.

It can also be noted the Alloy 1 has the slowest kinetics followed by Alloy 2 and Alloy 3 at all respective temperatures. This is due to the higher activation energy of the dislocation barrier in Alloy $1\left(64.38 \mathrm{~kJ} / \mathrm{mol}\right.$ at $\left.200{ }^{\circ} \mathrm{C}\right)$ at each temperature as compared to Alloy $2(54.59 \mathrm{~kJ} / \mathrm{mol}$ at $200{ }^{\circ} \mathrm{C}$ ) and Alloy $3\left(53.844 \mathrm{~kJ} / \mathrm{mol}\right.$ at $\left.200^{\circ} \mathrm{C}\right)$. The low activation energy by dislocation barrier can be correlated by its solid solution strengthening of austenite. More solid solution strengthening of austenite will have more resistance to atomic displacement during the bainite transformation. As it can be seen from Table 2, the austenite strength of Alloy 1 is maximum followed by Alloy 2 and Alloy 3. Therefore, it can be concluded that the kinetics of bainite transformation has its paramount dependence on the activation barrier by dislocation barrier and driving force available for transformation.

The rate of transformation (df/dt) (Fig. 4) is determined by the experimental data and model data. The experimental transformation rate observed to be in good agreement with the transformation rate determined by the proposed kinetic model. It can be observed that the transformation rate reduces with the reduction in the transformation temperature.

\subsection{Autocatalytic factor}

The proposed model formulates the value of autocatalytic factor by Eq. 33. This is a function of driving force, which changes with the carbon concentration of austenite during transformation, internal energy due to the shear stress of the dislocation and transformation temperature.

Table 2 The kinetic parameters used in the governing equation of model proposed in the present study

\begin{tabular}{|c|c|c|c|c|c|c|c|c|c|}
\hline \multirow[b]{2}{*}{$\mathrm{T}(\mathrm{K})$} & \multicolumn{3}{|c|}{ Alloy 1_0.98C [45] } & \multicolumn{3}{|c|}{ Alloy 2_0.83-1.54Co [45] } & \multicolumn{3}{|c|}{ Alloy 3_0.78-1.6Co [45] } \\
\hline & 473 & 523 & 573 & 473 & 523 & 573 & 473 & 523 & 573 \\
\hline $\mathrm{T}_{\mathrm{h}} \bar{X}(\mathrm{~K})$ & 608 & 608 & 608 & 633 & 633 & 633 & 658 & 658 & 658 \\
\hline $\mathrm{C}_{1}$ & 302 & 302 & 302 & 302 & 302 & 302 & 312 & 312 & 312 \\
\hline $\mathrm{T}_{0} \bar{X}(\mathrm{~K})$ & 590 & 590 & 590 & 600 & 600 & 600 & 600 & 600 & 600 \\
\hline $\mathrm{C}_{2}$ & 8487 & 8487 & 8487 & 8021 & 8021 & 8021 & 7703 & 7703 & 7703 \\
\hline $\mathrm{m}$ & 0.0104138 & 0.0104138 & 0.0104138 & 0.01177 & 0.01177 & 0.01177 & 0.01177 & 0.01177 & 0.01177 \\
\hline$Q_{G}^{*}(\mathrm{~kJ} / \mathrm{mol})$ & 148.3 & 154 & 156.3 & 146.4 & 150.6 & 156.7 & 143.4 & 149.3 & 152.7 \\
\hline $\mathrm{K}_{1}$ & 20.5 & 21 & 21.3 & 17 & 17 & 17 & 17 & 17 & 17 \\
\hline$\Delta G_{c h}^{\gamma \rightarrow a}(J / m o l)$ & -2325 & -1954 & -1580 & -2565 & -2200 & -1831 & -2809 & -2448 & -2077 \\
\hline d & 0.164 & 0.2 & 0.275 & 0.09 & 0.008 & 0.15 & 0.0035 & 0.09 & 0.1 \\
\hline$G_{i n t}(\mathrm{~J} / \mathrm{mol})$ & -1650 & -1550 & -1450 & -1550 & -1500 & -1395 & -1400 & -1380 & -1340 \\
\hline $\mathrm{Q}_{c}(\mathrm{~kJ} / \mathrm{mol})$ & 130 & 130 & 130 & 134 & 134 & 134 & 136 & 136 & 136 \\
\hline $\mathrm{Q}_{\mathrm{d}}(\mathrm{kJ} / \mathrm{mol})$ & 64.38 & 63 & 58.31 & 54.59 & 52.691 & 52.518 & 53.844 & 53.607 & 50.7 \\
\hline $\begin{array}{l}\text { Austenite strength } \\
\text { (MPa) [46] }\end{array}$ & 303.8 & 278.6 & 259 & 268.6 & 246.5 & 229.2 & 255.6 & 234.5 & 218 \\
\hline
\end{tabular}



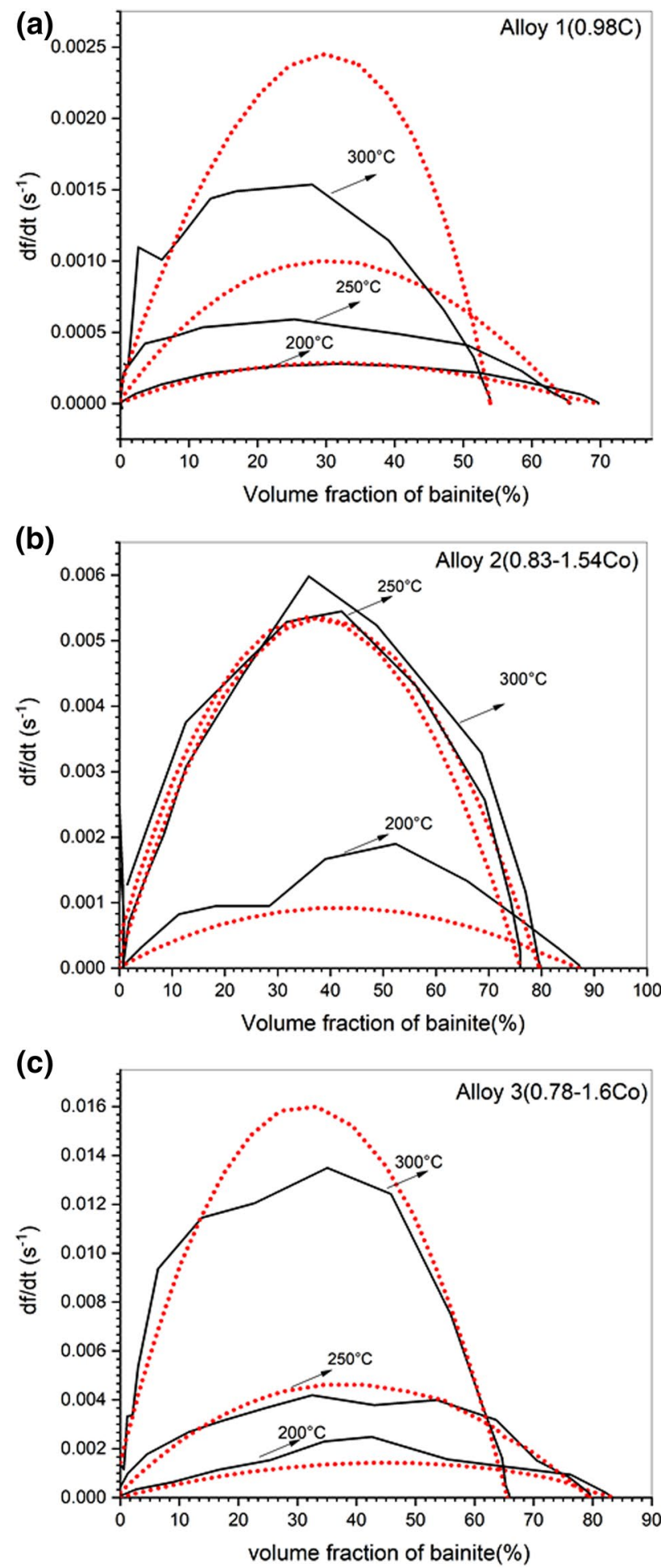

Fig. 4 Experimental [45] (solid lines) and calculated rate of transformation, df/dt (markers) of Alloy 1, Alloy 2 and Alloy 3

The autocatalytic factor is dynamic in nature and reduces with the volume fraction of transformation as shown in Fig. 5. This is due to a reduction in driving force available with an increase in carbon concentration during bainite transformation. Also, it can also be observed that the autocatalytic factor increases with reduction in transformation temperature as shown in Figs. 5, 6, 7 and Table 2. This is due to an increase in internal energy by an increase in a shear strain of bainite and reduction in transformation temperature. The internal energy due to shear strain of bainite is $1650 \mathrm{~J} / \mathrm{mol}$ at $200{ }^{\circ} \mathrm{C}, 1550 \mathrm{~J} / \mathrm{mol}$ at $250{ }^{\circ} \mathrm{C}$ and $1450 \mathrm{~J} / \mathrm{mol}$ at $300{ }^{\circ} \mathrm{C}$ (Table 2) which increases with reduction in temperature. Similarly for Alloy $2,1550 \mathrm{~J} / \mathrm{mol}$ at $200{ }^{\circ} \mathrm{C}, 1500 \mathrm{~J} / \mathrm{mol}$ at $250{ }^{\circ} \mathrm{C}$ and $1395 \mathrm{~J} / \mathrm{mol}$ at $300{ }^{\circ} \mathrm{C}$. These internal energy values are in good agreement with the reported energy values for martensitic transformation [12].

\subsection{Validation of interaction energy term}

Validity of concept of interaction energy can be done by determination of macroscopic averaged transformation strain on surrounding austenite as given by Eq. 7. Using the values of $\mathrm{G}_{\mathrm{int}}$ from kinetic model proposed in the present work and tabulated in Tables 1 and 2, the macroscopic averaged transformation strain in tensile direction in range of 0.052-0.058 as shown in Table 2. The values of the macroscopic averaged transformation strain of bainite embryo are found to be at per as also reported in literature [27-29] (Table 3).

\subsection{Carbon concentration in retained austenite}

Carbon content in bainite, $\mathrm{w}_{\mathrm{b}}$, is an extremely important parameter and is a sensitive parameter used in the present kinetic model. It is adjusted such that the volume fraction of bainite has a coherent match with the experimental data. $w_{b}$ gives a measurement of the carbon distribution during the transformation of bainite. It influences significantly with the transformation temperature. Carbon content in bainite, $\mathrm{w}_{\mathrm{b}}$ is dependent on the volume fraction of bainite $(f)$. As the volume fraction of bainite $(f)$ increases, the influence of $w_{b}$ also rises. This indicates that $\mathrm{w}_{\mathrm{b}}$ plays a greater role during later stages of the bainite transformation than at the start of the transformation. If carbon were completely partitioned from bainitic ferrite into retained austenite during the transformation, $w_{b}$ would attain a value of 0 . However, its value never reaches zero due to the solid solubility of carbon in bainite due to the presence of a large quantity of defects. As the degree of carbide precipitation increases or super saturation of carbon in bainite due to the presence of a large quantity of defects, the value of $w_{b}$ also increases and attains a maximum value of $\bar{w}$. Using lever rule it can be observed at $\mathrm{w}_{\mathrm{b}}=\bar{w}, 100 \%$ 

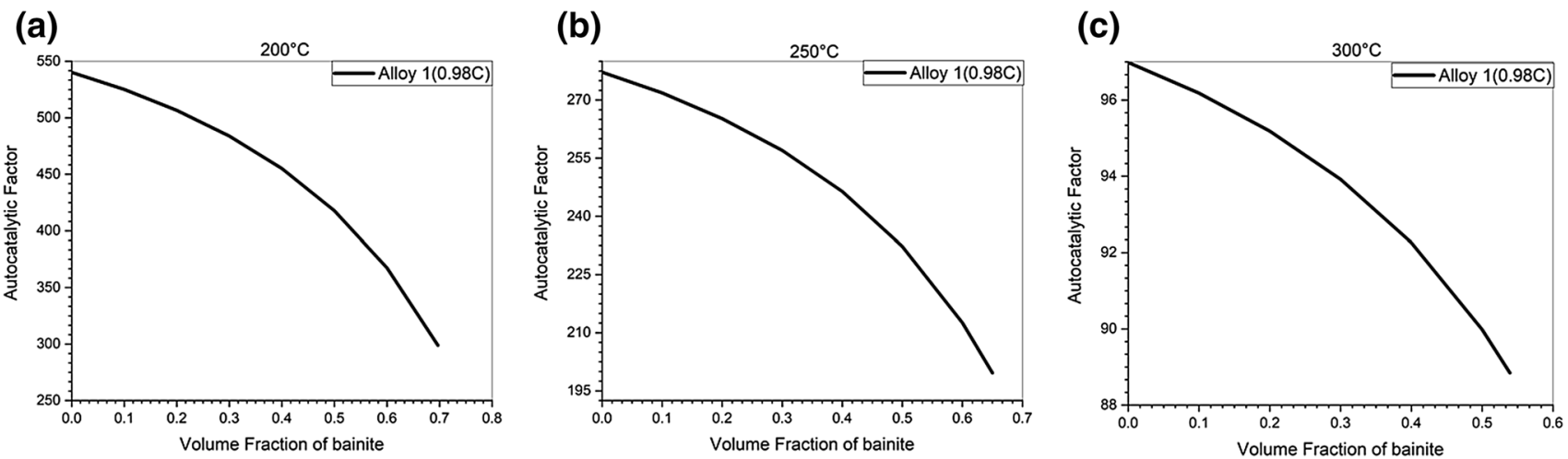

Fig. 5 The autocatalytic factor at different transformation temperatures as a function of volume fraction of bainite for Alloy $1 \_0.98 \mathrm{C}$

(a)

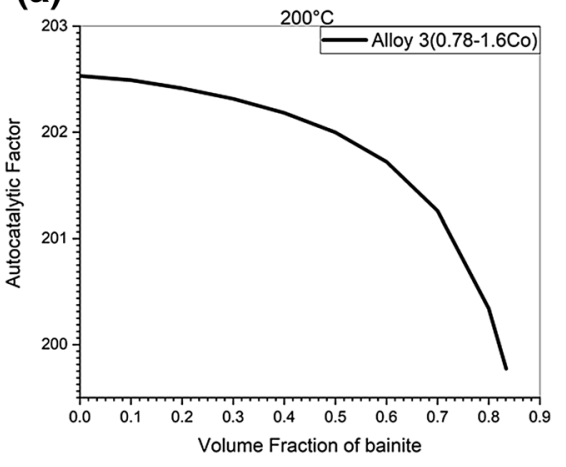

(b)

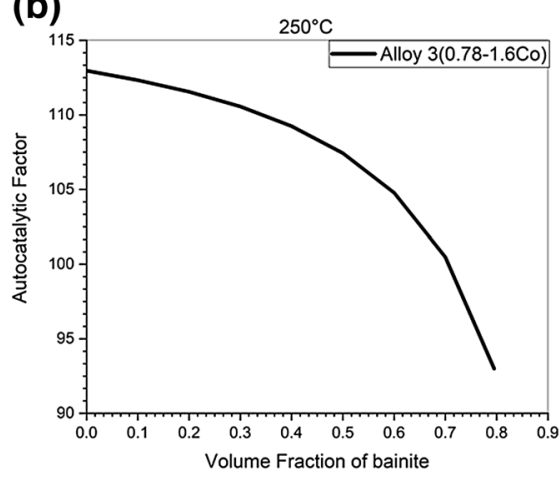

(c)

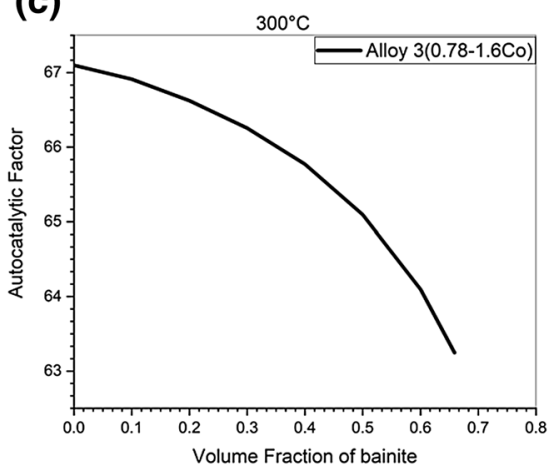

Fig. 6 The autocatalytic factor at different transformation temperatures as a function of volume fraction of bainite for Alloy 2_0.83-1.54Co
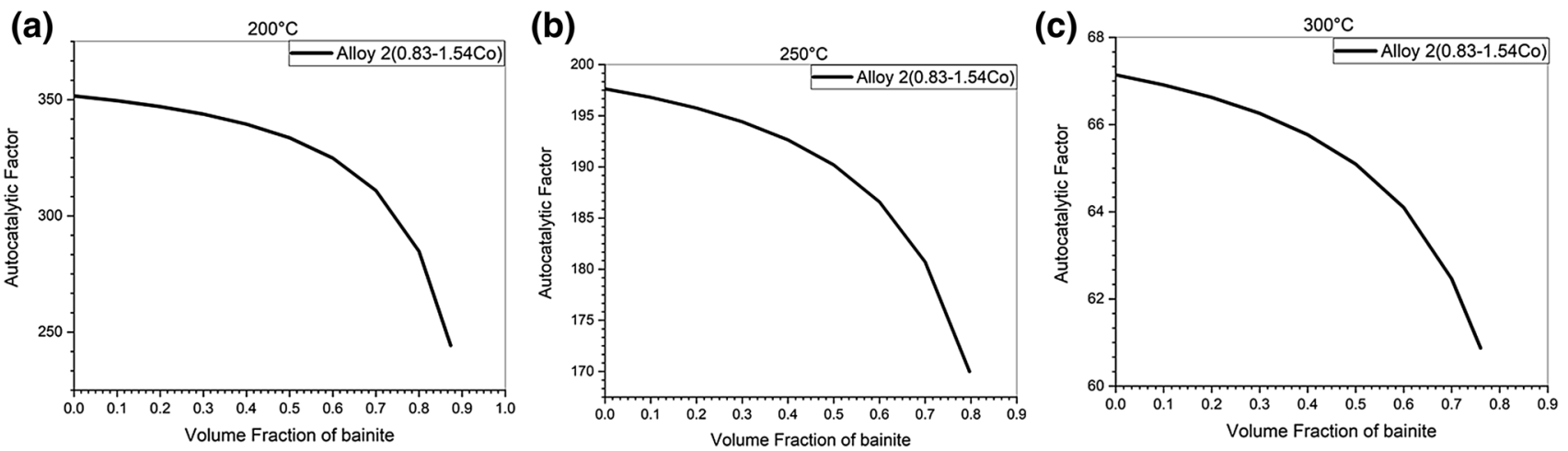

Fig. 7 The autocatalytic factor at different transformation temperatures as a function of volume fraction of bainite for Alloy 3_0.78-1.6Co

bainite formation would occur in this case which is not possible. Therefore the value of $\mathrm{w}_{\mathrm{b}}$ is between 0 and $\bar{w}$. Due to the significance of $w_{b}$, the fit values obtained for $\mathrm{w}_{\mathrm{b}}$ must be validated properly from the theoretical values of carbon concentration.

In the calculation of carbon concentration in bainite and austenite, the values of $x_{b}$ are adjusted to account for the degree of super saturations, which also depends on the temperature of transformation. It is observed that the carbon level in Alloy 1, Alloy 2 and Alloy 3 respectively are almost close to $T_{0}^{\prime}$ line calculated using Thermocalc. The differences observed in simulated and theoretical values obtained by thermodynamic calculation as shown in Fig. 8 ( $T_{0}^{\prime}$ temperature) [40] are because of 
Table 3 The data involved in the validation of interaction energy of bainite embryo and stress field of bainite

\begin{tabular}{llll}
\hline & $T(\mathrm{~K})$ & $G_{\text {dis }}(\mathrm{J} / \mathrm{mol})$ & $\begin{array}{l}\text { Shear strain } \\
\text { calculated }\end{array}$ \\
\hline Alloy 1_0.98C [45] & 473 & 1650 & 0.058 \\
& 523 & 1550 & 0.056 \\
& 573 & 1450 & 0.054 \\
Alloy 2_0.83-1.54Co [45] & 473 & 1550 & 0.056 \\
& 523 & 1500 & 0.055 \\
Alloy 3_0.78-1.6Co [45] & 573 & 1395 & 0.0538 \\
& 473 & 1400 & 0.0539 \\
& 523 & 1380 & 0.05356 \\
& 573 & 1340 & 0.05278 \\
\hline
\end{tabular}

the model assumption of the carbon concentration to be homogeneous throughout the austenite i.e. meanfield approximations. The alloy 1 , alloy 2 and alloy 3 were found to exhibit the incomplete reaction phenomenon, as the transformation to bainite stops well ahead of equilibrium temperature and the remaining austenite acquires its para-equilibrium carbon content.

Experimental results shown in Fig. 8 indicates that in some cases the measured carbon concentrations exceed the $T_{0}^{\prime}$ concentration and not in others. This is a consequence of the fact that the retained austenite films entrapped between neighboring sub-units of bainite have higher carbon concentration than the blocks of retained austenite located between the sheaves of bainite, which may transform to martensite during subsequent quenching. This inhomogeneous distribution of carbon will allow the transformation to proceed to an extent somewhat greater than that allowed by thermodynamic conditions based on an uniform carbon assumption.

Alloy 1 having least Gibbs free energy among other alloys, it has more probability to form more blocky austenite and thus it shows more carbon concentration than $T_{0}^{\prime}$ line.

In alloy 2, which has relatively larger Gibbs free energy than alloy 1 generates finer bainite lath and more dislocation density in bainite and thus may have more probability of trapping carbon in defects in bainite.

In alloy 3 which have largest Gibbs free energy will tend to produce more finer bainite and more dislocations in bainite. Thus, the carbon gets trapped in these dislocations and retained austenite has lesser carbon than $T_{0}^{\prime}$. and thus it less carbon concentration than $T_{0}^{\prime}$ line.
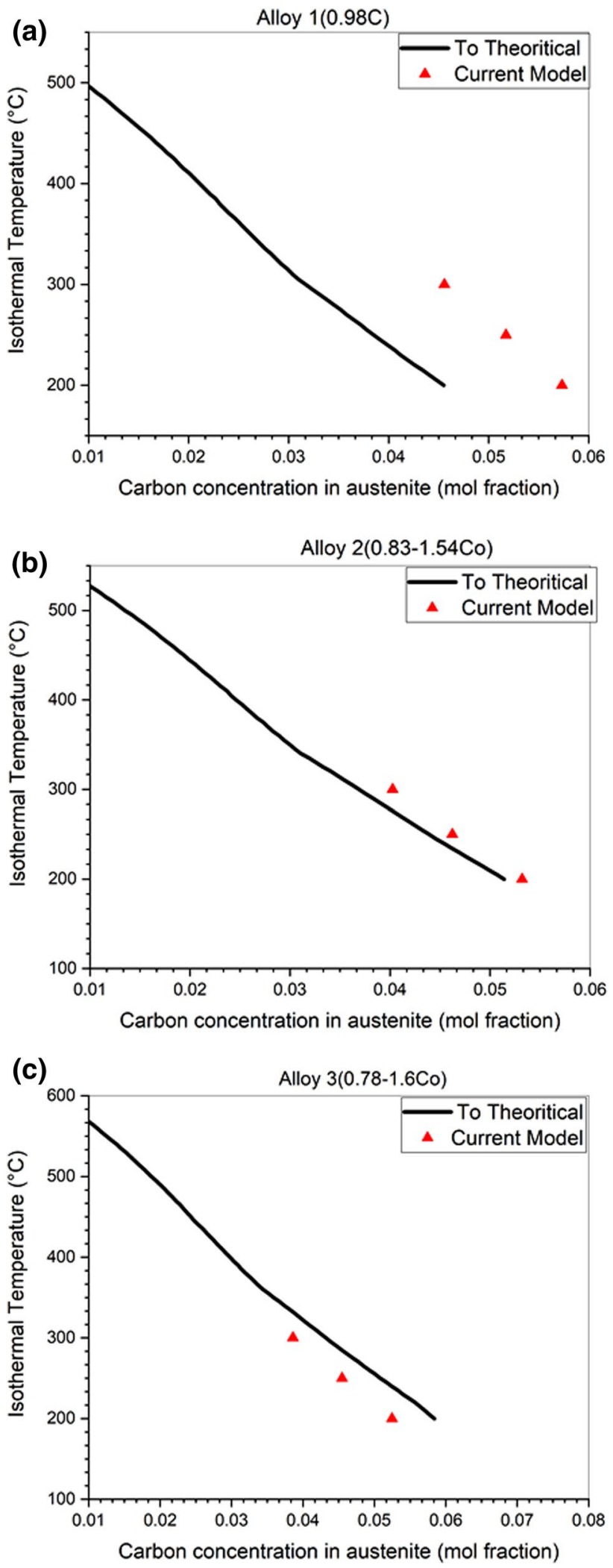

Fig. 8 Comparison of Carbon concentration in austenite at the end of the transformation in Alloy 1_0.98C, Alloy 2_0.83-1.54Co and Alloy 3_0.78-1.6Co obtained from model and by theoretical calculation $\left(T_{0}^{\prime}\right)[40]$ 


\section{Conclusions}

1. A kinetic model has been proposed in the present work, which involves an extra driving force component involved in nucleation by autocatalysis. The autocatalytic nucleation of bainite transformation in steels will be assisted by the presence of dislocations in austenite formed near transformed bainite, which will reduce the nucleation barrier of bainite formation.

2. The model also evaluates the activation energy due to dislocation barrier. It is found to increase with a reduction in transformation temperature because of its dependency on solid solution strengthening of austenite.

3. The slow kinetics at low transformation temperature is due to larger activation energy due to dislocation barrier as it as higher solid solution strengthening of austenite and the greater resistance to atomic displacement during transformation.

4. The autocatalytic factor is dynamic in nature and reduces with the volume fraction of transformation. This is due to a reduction in driving force with an increase in carbon concentration during bainite transformation.

5. It has been found that the autocatalytic factor increases with reduction in transformation temperature. This is due to an increase in internal energy by an increase in a shear strain of bainite and reduction in transformation temperature.

6. The interaction energy of shear strain of dislocation and embryo was validated by determining the transformation shear strain in austenite was found to be in the range as reported in literature for bainitic transformations.

Acknowledgements The authors are thankful to the Director, CSIRNational Metallurgical Laboratory, India for providing the necessary funding through in house iPSG project OLP-0305.

\section{Compliance with ethical standards}

Conflict of interest The authors declare that they have no conflict of interest.

\section{References}

1. Hehemann RF, Kinsman KR, Aaronson HI (1972) A debate on the bainite reaction. Metall Trans 3:1077

2. Ohmori Y, Maki T (1991) Bainitic transformation in view of displacive mechanism. Mater Trans, JIM 32:631

3. Muddle BC, Nie JF (2002) Formation of bainite as a diffusionaldisplacive phase transformation. Scr Mater 47:187
4. Aaronson HI, Reynolds WT, Shiflet GJ, Spanos G (1990) Bainite viewed three different ways. Metall Trans A 21:1343

5. Bhadeshia HKDH (2001) Bainite in steels. The Institute of Materials, London

6. Ghosh G, Raghavan V (1986) The kinetics of isothermal martensitic transformation in an Fe-23.2wt.\% Ni-2.8wt. \% Mn alloy. Mater Sci Eng 80:65-74

7. Cohen M (1972) Operational nucleation in martensitic transformations. Metall Trans 3(5):1095-1098

8. Ghosh G, Olson GB (1994) Kinetics of F.C.C. $\rightarrow$ B.C.C. heterogeneous martensitic nucleation-I. The critical driving force for athermal nucleation. Acta Metall Mater 42(10):3361-3370

9. Ghosh G, Olson GB (1994) Kinetics of F.C.C $\rightarrow$ B.C.C. heterogeneous martensitic nucleation-II. Thermal activation. Acta Metall Mater 42(10):3371-3379

10. Meng QP, Rong YH, Hsu TY (2006) Effect of internal stress on autocatalytic nucleation of martensitic transformation. Metall Mater Trans A 37(5):1405-1411

11. Matsuda H, Bhadeshia HKDH (2004) Kinetics of the bainite transformation. Proc R Soc Lond A 460(1):1707-1722

12. Singh SB (1998) Phase transformations from deformed austenite. Ph.D. Thesis, University of Cambridge, Cambridge, UK

13. Sidhu G, Bhole SD, Chen D, Essadiqi E (2011) An improved model for bainite formation at isothermal temperatures. $\mathrm{Scr}$ Mater 64(1):73-76

14. van Bohemen SMC, Sietsma J (2008) Modeling of isothermal bainite formation based on the nucleation kinetics. Int J Mater Res 99(7):739-747

15. Van Bohemen SMC (2010) A modeling start curves of bainite formation. Metall Mater Trans A 41:285

16. van Bohemen SMC (2013) Autocatalytic nature of the bainitic transformation in steels: a new hypothesis. Phil Mag 93(4):388-408

17. Santofimia J, Caballero FG, Capdevila C, Garcia-Mateo C, de Andrés Maria CG (2006) New model for the overall transformation kinetics of bainite. Part 2: validation. Mater Trans 47(10):2473-2479

18. Ravi AM, Sietsma J, Santofimia MJ (2016) Exploring bainite formation kinetics distinguishing grain-boundary and autocatalytic nucleation in high and low-Si steels. Acta Metall 105:155-164

19. Olson GB, Cohen M (1976) A general mechanism of martensitic nucleation: part III. Kinetics of martensitic nucleation. Metall Trans A 7:1915-1923

20. Ravi AM, Sietsma J, Santofimia MJ (2017) Bainite formation kinetics in steels and the dynamic nature of the autocatalytic nucleation process. Scr Mater 140:82-86

21. Bhadeshia HKDH, Christian JW (1990) Bainite in steels. Metall Trans A 21:767-797

22. Bhadeshia HKDH (1981) A rationalisation of shear transformations in steels. Acta Metall 29:1117-1130

23. Chester NA, Bhadeshia HKDH (1997) Mathematical modelling of bainite transformation kinetics. J Phys IV 7:41-46

24. Garcia-Mateo C, Bhadeshia H (2004) Nucleation theory for high-carbon bainite. Mater Sci Eng A 378:289-292 (European Symposium on Martensitic Transformation and Shape-Memory)

25. Santofimia MJ, Caballero FG, Capdevila C, Garcia-Mateo C, de Andres CG (2006) Evaluation of displacive models for bainite transformation kinetics in steels. Mater Trans 47:1492-1500

26. San Martin D, Aarts KWP, Rivera-Díaz-del-Castillo PEJ, van Dijk NH, Bruck E, van der Zwaag S (2008) Isothermal martensitic transformation in a $12 \mathrm{Cr}-9 \mathrm{Ni}-4 \mathrm{Mo}-2 \mathrm{Cu}$ stainless steel in applied magnetic fields. J Magn Magn Mater 320:1722-1728

27. Messner C, Reisner G, Sun QP, Werner E (2000) On instabilities and autocatalytic effects associated with the nucleation of 
martensite bands in polycrystalline SMA flat tensile specimens. Comput Mater Sci 19:313-319

28. Shaw JA, Kyriakides S (1997) On the nucleation and propagation of phase transformation fronts in a NiTi alloy. Acta Mater 45(2):683-700

29. Song GQ, Sun $Q P$, Cherkaoui M (1999) Role of microstructure in the thermomechanical behavior of SMA composites. J Eng Mater Technol 121:86-92

30. Olson GB, Cohen M (1982) In: Aaronson HI et al. (eds) Proceedings of the international conference on solid-solid phase transformations. AIME, pp 1145-1164

31. Kaufman L, Cohen M (1958) Thermodynamics and kinetics of martensitic transformations. Prog Metal Phys 7:165-246

32. Cohen M (1958) Nucleation of solid state transformations. Trans AIME 212:171-183

33. Eshelby JD (1959) The elastic field outside an ellipsoidal inclusion. Proc R Soc A 252:561-569

34. Rees Gl, Bhadeshia HKDH (1992) Bainite transformation kinetics: part I modified model. Mater Sci Technol 8:985-993

35. Magee CL (1970) The nucleation of martensite. In: Phase transformations: American society of metals, p 115

36. Gaude-Fugarolas D, Jacques PJ (2006) A new physical model for the kinetics of the bainite transformation. ISIJ Int 46:712

37. Koistinen DP, Marburger RE (1959) A general equation prescribing the extent of the austenite-martensite transformation in pure iron-carbon alloys and plain carbon steels. Acta Mater 7:59

38. Van Bohemen SMC, Sietsma J, Hermans MJM, Richardson IM (2003) Kinetics of the martensitic transformation in low-alloy steel studied by means of acoustic emission. Acta Mater 51:4183
39. Bhadeshia HKDH, Edmonds DV (1979) The bainite transformation in a silicon steel. Metall Trans A 10A:895-907

40. Peet MJ, MAP_STEEL_MUCG83, An enhanced version of MAP_ STEEL_MUCG46 but with the four additional elements: Co, Cu, $\mathrm{Al}$ and W. Corrects an inconsistency in MUCG73. https://www. phase-trans.msm.cam.ac.uk/map/steel/programs/mucg83.html

41. Gegner J, Vasilyev AA, Wilbrandt P-J, Kaffenberger M (2012) Alloy dependence of the diffusion coefficient of carbon in austenite and analysis of carburization profiles in case hardening of steels. In: Conference: MMT'2012, At Ariel University Center of Samaria, Ariel, Israel, vol 10, pp 1-261

42. Liu D, Gao Y, Gear CW (1978) Numerical initial value problem in O.D.E. ed Fei Jinggao. Science Press, Beijing, pp 165-203

43. Bopei $F(1982)$ The GEAR program for solving initial value problems in general or stiff ordinary differential equations. Numer Calc Comput Appl 3:12-23

44. Day JD, Murthy DNP (1983) A comparison of some ODE solvers which require Jacobian evaluations. J Comput Appl Math 9:213-219

45. Garcia-Mateo C, Caballero FG, Bhadeshia HKDH (2003) Acceleration of low-temperature bainite. ISIJ Int 43:1821-1825

46. Young $\mathrm{CH}$, Bhadeshia HKDH (1994) The strength of mixtures of bainite and martensite. Mater Sci Technol 10:209-214

Publisher's Note Springer Nature remains neutral with regard to jurisdictional claims in published maps and institutional affiliations. 